Filo. y Lingüí. 9(1): 103-122, 1983.

\title{
ANALISIS DEL POEMA "UNIDAD EN ELLA" DE VICENTE ALEIXANDRE
}

María Elia Rodríguez Herrera

\section{INTRODUCCION}

Al enfrentarnos al hecho poético y querer cxptarlo en su esencia, son muchos y variados los procedimientos que encontramos. Van desde consicieraciones puramente subjetivas, como explicar la emoción que pueden despertar unos versos, hasta hacer complejas y sofisticadas "disecciones" de las obras, mediante las cuales se reduce lo poético a meras formalizaciones, vacías de significado real y completo.

Dichosamente hay matices en estos extremos y entre ellos hemos buscado un medio de acercamiento objetivo - si no científico- al hecho lírico.

Hemos de partir de tres consideraciones básicas.

En primer lugar concebimos el poema como un mensaje verbal, estructurado según sus propias leyes. Es decir, como

"Una realidad lingüística valedera en sí misma y constituida por diversos niveles o relaciones del lenguaje, básicamente el nivel fónico y el semántico (1)".

En segundo lugar consideramos fundamental en la escritura poética el hecho de que todo elemento en ella es significativo, nada es contingente (2).

En tercer lugar nos interesa destacar la motivación del signo lingüístico que se da en la poesía y de la cual afirma Genette:

"...la función poética reside precisamente en ese esfuerzo por 'remunerar' aunque fuera ilusoriamente, la arbitrariedad del signo, es decir, 'motivar el lenguaje' " (3).

Tomando como base las anteriores consideraciones analizamos el poema "Unidad en ella" de Vicente Aleixandre, para explicar los diferentes niveles de su lenguaje, encontrar la significación del poema y poder comprobar que:

"En poesía toda semejanza perceptible de sonido se evalúa con relación a la semejanza y/o desemejanza de significado" (4).

Los fundamentos teórico-metodológicos para lograr lo anterior nos los proporcionaron las ideas de Julien A. Greimas (5) y Samuel Levin (6).

De Greimas tomamos el concepto de isotopía (7) para estudiar el nivel semántico del lengua- je, ya que el estudio de las isotopías se refiere a la relación entre los diferentes niveles (fonológico, morfológico, léxico, sintáctico, semántico, simbólico) y la motivación del signo literario frente a la inmotivación saussuriana del signo lingüístico natural (8).

Basamos el análisis de "Unidad en ella" siguiendo el modelo greimasiano, en el principio de que el texto poético, por su carácter plurisignificativo puede ser leído en diferentes planos isótopos (9). Cada uno de estos nos conduce hacia una isotopía, la cual está conformada por series redundantes o equivalentes de lexemas, que debemos inventariar. Posteriormente, a estas unidades portadoras de la significación hemos de extraerles las semas o "propiedades de los términos-objeto" (10) para ir delimitando la serie de oposiciones binarias sobre las que descansa la isotopía.

Como complemento y apoyo al estudio semántico, Samuel Levin nos proporciona el concepto de "coupling" (11), el cual permite relacionar otros niveles (fónico, sintáctico, morfológico), con la significación, para comprobar que el poema es una unidad indivisible de sentido.

\section{Descripción formal del poema}

El poema describe el anhelo de unión del yo lírico con un tú dual, dicotómico, eminentemente ambiguo en su esencialidad.

Esa "Unidad en ella" se materializa en una doble manifestación erótico-telúrica: la mujer-cosmos, que será, por un lado, actante objeto del amor carnal, y por otro lado, la teluricidad primigenia del universo, matizada, sin embargo de la eroticidad, en el sentido místico. (véase al respecto la nota 21).

Está organizada la composición con base en dos planos hacia los que tiende ese yo: el real, que sugiere con imágenes fugaces pero de gran fuerza expresiva la unión erótica indicada con un beso:

\footnotetext{
"Tu forma externa...

cráter que me convoca con su música íntima con esa indescifrable Ilamada de tus dientes"
}

Y el metafórico, que remite en forma inexorable a la fusión con el cosmos (12): 
"quiero ser tú, tu sangre, esa lava rugiente que regando encerrada bellos miembros extremos siente así los hermosos límites de la vida".

La fusión de ambos planos aparece como la eséncia de la manifestación poética que ya se anuncia en el título mismo del poema "Unidad en ella" y que reitera en el verso final de la composición:

"Este beso...

que nunca podría destruir la uniaad de este mundo"

Desde el punto de vista puramente formal, exterior, el poema consta de seis estrofas, cinco de cuatro versos y la última, mayor, de siete.

Las dos primeras describen sinecdóquicamente al tú-objeto destacando las cualificaciones (fugacidad, tersura, luminosidad) de los miembros aludidos:

\footnotetext{
"1 Cuerpo feliz que fluye entre mis manos, rostro amado donde contemplo el mundo, donde graciosos pájaros se copian fugitivos, volando a la región donde nada se olvida.

Tu forma externa, diamante o rubí duro, brillo de un sol que entre mis manos deslumbre cráter que me convoca con su música íntima, con esa indescifrable llamada de tus dientes".
}

Estas dos estrofas son eminentemente pictóricas; en ellas hay un encadenamiento de adjetivaciones referidas al tú, que se manifiestan en forma de subordinaciones relativas en la primera estrofa:

"Cuerpo feliz /que fluye...

rostro amado /donde contemplo el mundo ldonde graciosos pájaros se copian..."

En la segunda estrofa, en cambio, se combinan sustantivos en función adjetival y oraciones subordinadas:

"Tu forma externa /diamante o/rubi duro brillo de un sol /que deslumbra cráter lque me convoca..."

Es evidente, además, la elisión del verbo principal (13) en estas estrofas, lo cual refuerza el carácter estático del tú, como veremos más adelante.

Vemos así que del verso 1 al 8 hay una continuidad cualificativa que parte del ser antropomórfico ("cuerpo feliz") y se va desdibujando en formas cósmicas ("Brillo de un sol", "cráter que me convoca").

A partir del verso 9, inicio de la tercera estrofa el encadenamiento va a configurarse mediante acciones que expresan la voluntad precisa, definida del yo lírico ("muero", "me arrojo", "quiero").

La conjunción porque se reitera en los versos 9 y 10 para encadenar las causas del deseo expreso del yo: su fusión amorosa con el tú, que es muerte individual y vida cósmica a la vez:

"Muero...

$\begin{array}{ll}9 & \text { porque me arrojo } \\ 9 & \text { porque quiero morir } \\ 10 & \text { porque quiero vivir en el fuego } \\ 11 & \text { porque este aire fuera no es mío sino el } \\ & \text { caliente aliento..." }\end{array}$

Hay en esta estrofa un juego conceptual entre vida y muerte que se confunden y se anhelan, en una dialéctica existencial:

"Muero... porque quiero morir porque quiero vivir en el fuego..."

Esta estrofa se completa con la $5^{\mathrm{a}}$ especialmente en los versos 17 y 18 , los cuales reafirman la concepción dialéctica del amor en Aleixandre:

17 "Quiero amor o la muerte, quiero morir del todo, 18 quiero ser tú, tu sangre..."

El amor es muerte y la muerte amor. Y la manifestación plena del amor es la fusión del yo con el tú ("Quiero ser tú...").

Esa fusión permite pasar del plano puramente humano al cósmico, universal que es principio y fin de la vida:

12 "porque quiero vivir en el fuego..."

13 “...teñido del amor,

14 enrojecido el rostro por tu purpúrea vida"

la fusión yo-tú, además, borra los límites de la individualidad, al conseguir la unidad plena, cósmica:

18 "quiero ser tú..." (14)

Hemos de destacar la aparente influencia de los filósofos presocráticos, especialmente Empédocles y los mecanicistas, en la concepción aleixandrina del amor como destrucción en el poemario (titulado precisamente La Destrucción o el amor), al que pertenece el poema que analizamos.

Según los mecanicistas, la pugna entre amor y odio es la fuerza motora del cosmos, de ahí la di- 
cotomía siempre presente de amor/destrucción (15).

Asimismo es importante resaltar la influencia de los místicos españoles, especialmente Santa Teresa, con la identificación que hace del amor-pasión y el amor-divino. Aunque, claro está, para Aleixandre la identificación es con el amor-cósmico, con el universo como principio y fin de vida. Es lo que Carlos Bosoño llama "misticismo panteísta" (16). El propio autor se denomina "místico de la materia" (17).

En este sentido, es notable la semejanza de Santa Teresa con las estrofas 3 y 5 del poema. Veamos:

\section{Aleixandre}

"Muero porque me arrojo, porque quiero morir porque quiero vivir en el fuego, porque este aire de afuera no es mío, sino el caliente aliento

que si me acerco quema y dora mis labios desde un fondo. ...

Quiero amor o la muerte, quiero morir del todo, quiero ser tú, tu sangre, esa lava rugiente que regando encerrada bellos miembros extremos siente así los hermosos límites de la vida".

La estrofa sexta y última, más larga que las otras ( 7 versos), cierra el poema con una estructura adjetival enumerativa similar a la de la primera estrofa.

Contiene una doble reiteración cualificativa, que se explicita mediante dos elementos: el término comparativo "como" y la cópula "es", sustituida, esta última, por la coma (,) a partir del verso 24 , recurso de elipsis ya analizado anteriormente (ver pág. 104 y nota 13).

"Deja, deja que mire..

deja que mire el hondo clamor de tus entrañas

donde muero y renuncio a vivir para siempre".

La $5^{\mathrm{a}}$ estrofa, a la que ya nos hemos referido parcialmente, también se organiza mediante la reiteración de un elemento. En esta ocasión es el deseo expreso, voluntarioso del yo, contenido en la forma verbal "quiero":

17 "Quiero amor o la muerte

17 quiero morir del todo

18 quiero ser tú, tu sangre..."

El objeto del deseo es la fusión con el tú (mujer-cosmos), principio y fin de la vida y la muerte:

18 "tú, tu sangre, esa lava rugiente

19 que regando encerrada bellos miembros extremos

20 siente así los hermosos límites de la vida"

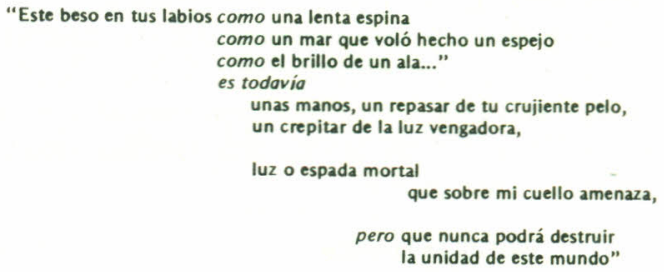

El primer conjunto cualificativo (versos 21 al 23) remite, como en las dos primeras estrofas (versos 1 al 8), a lo fugaz, a lo terso, lo luminoso de esa unión amorosa con el tú:

beso como "un mar que voló hecho un espejo" el brillo de un ala..." 
Hay, sin embargo, un elemento que introduce de nuevo la dicotomía amor-muerte:

21 beso como "una lenta espina"

Es el clásico beso que mata, pues contiene en sí el germen de la vida y de la muerte.

En las tres cualificaciones citadas (versos 21, 22 y 23) la unión remite al tú-cósmico.

A partir del verso 24 , en que aparece la forma verbal "es" para enumerar predicaciones nominales de la unión, el tú vuelve a aparecer, umbiguamente, como sinécdoque del objeto-mujer y del objeto-cosmos. Esta incertidumbre la señala, certeramente, el adverbio "todavía":

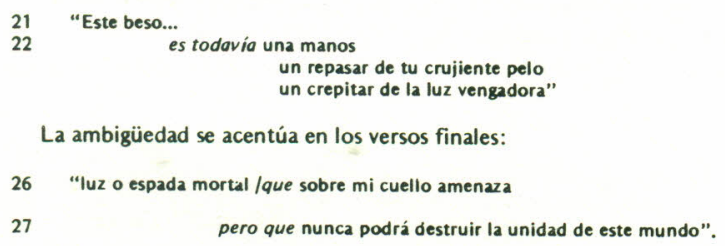

El beso que mata y que da vida es "espada" o la "luz", es "Unidad en ella" o "unidad de este mundo". La conjunción adversativa "pero" reafirma el contenido semántico del título y del final del poema, que se fusionan en una sola unidad erótico-telúrica.

\section{Análisis isotópico del plano semántico del poe- ma}

Partiendo de los supuestos metodológicos planteados por Greimas, y a los cuales nos hemos referido en la introducción, descubriremos los dos planos isotópicos que conforman "Unidad en ella", y que remiten a las dos isotopías básicas del poema: la isotopía erótica y la isotopía telúrica.

La unidad semántico-estructural del poema, sin embargo, va a estar dada por la isotopía englobante de estas dos, y a la que denominamos isotopía de la Unidad. Esta última será también objeto de análisis y descripción.

\subsection{Isotopía erótica :}

Se configura a partir del eje de la sexualidad, cuyos extremos están dados en el poema por el tú y el yo líricos.

El tú conlleva el sema "femeneidad", y el yo, "masculinidad". Ambos van a remitir el acto erótico de la unión amorosa, manifestada metonímicamente por el beso:

"esa indescifrable llamada de tus dientes"

"el caliente aliento/que si me acerco quema y dora mis labios desde un fondo".

El tú y el yo aparecen sinecdóquicamente expresados, como si esa manifestación parcial de sus miembros sólo se lograra soldar con la unidad amorosa, que es fusión y vida a la vez.

El cuadro número uno recoge las manifestaciones lexemáticas sinecdóquicas del tú y del yo.

CUADRO No. 1

\section{MANIFESTACIONES LEXEMATICAS DEL TU Y DEL YO}

\section{SEXUALIDAD}

MASCULINIDAD

\begin{tabular}{|c|c|}
\hline $\begin{array}{l}\text { Yo (Como desinencia } \\
\text { verbal) }\end{array}$ & $\begin{array}{l}\text { tú } \\
\text { ella }\end{array}$ \\
\hline El rostro & Rostro amado \\
\hline Mis labios & $\begin{array}{l}\text { Tus labios } \\
\text { this dientes }\end{array}$ \\
\hline Mi cuello & $\begin{array}{l}\text { Cuerpo feliz } \\
\text { Tu forma externa } \\
\text { Bellos miembros extremos } \\
\text { Tu crujiente pelo }\end{array}$ \\
\hline Mis manos & Unas manos \\
\hline & $\begin{array}{l}\text { Tu purpúrea vida } \\
\text { Tus entrañas } \\
\text { Tu sangre. }\end{array}$ \\
\hline
\end{tabular}

Evidentemente el poema recarga la manifestación lexemática en el polo femenino, al que se alude no sólo en su exterior ("cuerpo", "rostro", "labios", "dientes", "miembros", "manos", "pelo"), sino también en su esencialidad vital ("vida", "sangre", "entrañas").

Ese recargo es explicable, por cuanto el tú-individual de esta isotopía va a servir de paso al tú-cósmico de la isotopía telúrica, es decir, en el tú se efectuarán los procesos de suspensión y sustitución sémicos (19).

Por otra parte, la estructuración del poema, como ya dijimos en la descripción formal (apartado 2 de este trabajo), descansa en primera instancia en una red cualificativa que enmarca e individualiza al tú, mujer y cosmos.

El cuadro número dos contiene las cualificaciones del tu, con sus manifestaciones metafóricas y sinecdóquicas o metonímicas. 
CUADRO No. 2

\section{INVENTARIO CUALIFICATIVO DEL TU}

\begin{tabular}{l|l}
$\begin{array}{l}\text { Manifestación } \\
\text { metonímica }\end{array}$ & $\begin{array}{l}\text { Manifestación } \\
\text { Metafórica }\end{array}$ \\
\hline Cuerpo feliz & $\begin{array}{l}\text { Que fluye } \\
\text { Graciosos } \\
\text { pájaros } \\
\text { fugitivos, } \\
\text { volando }\end{array}$ \\
\hline Forma externa & $\begin{array}{l}\text { diamante } \\
\text { rubí duro } \\
\text { brillo de sol que } \\
\text { deslumbra } \\
\text { Cráter que me } \\
\text { convoca }\end{array}$ \\
\hline Llamada de tus dientes & $\begin{array}{l}\text { música íntima } \\
\text { hondo clamor } \\
\text { de tus extrañas }\end{array}$ \\
\hline $\begin{array}{l}\text { Caliente aliento } \\
\text { tu sangre }\end{array}$ & $\begin{array}{l}\text { purpúrea vida } \\
\text { lava rugiente }\end{array}$ \\
\hline Bellos miembros extremos & $\begin{array}{l}\text { un repasar de tu } \\
\text { crujiente pelo }\end{array}$ \\
\hline Unas manos &
\end{tabular}

Las sinécdoques y metonimias dibujan al tú en su contorno y en su interior. Los semas "humanidad", "vitalidad", "amor", "suavidad", "receptividad", "calidez", "Ilamado", "color", se extraen de las cualificaciones del tú.

Metafóricamente el tú adquiere matices telúri$\cos$, cósmicos: "fugacidad", "luminosidad", "fluidez", "profundidad", "fuerza", "teluricidad", "sonoridad". Estas cualificaciones remitirán, en otra lectura, a la isotopía telúrica.

Las cualificaciones del yo, recogidas en el cuadro número tres se extraen de los lexemas funcionales con que se manifiesta el yo en el poema, y ofrecen así una primera oposición: a ıa aglomeración adjetival de las estrofas 10 y 20 referidas al tú, se opone un abigarrado conjunto de acciones contrastantes:

$$
\begin{array}{ccc}
\text { vivir } & \text { morir } \\
\text { desear } / & \text { renunciar, etc. }
\end{array}
$$

Las cuales configuran el campo semántico del yo.

\section{CUADRO No. 3}

INVENTARIO LEXEMATICO DEL YO

\begin{tabular}{l|l}
$\begin{array}{l}\text { MANIFESTACION } \\
\text { CUALIFICATIVA }\end{array}$ & $\begin{array}{l}\text { MANIFESTAC } \\
\text { FUNCIONAL }\end{array}$ \\
\hline [el rostro] teñido del amor & $\begin{array}{l}\text { Contemplo, miro } \\
\text { Quero } \\
\text { Quiero ma muert } \\
\text { Renuncio a vivi } \\
\text { para siempre } \\
\text { me arrojo } \\
\text { me acerco. }\end{array}$ \\
[el rostro] enrojecido & $\begin{array}{l}\text { Quiero vivir en } \\
\text { el fuego } \\
\text { Quiero ser tú. } \\
\text { Quiero amor }\end{array}$ \\
&
\end{tabular}

Es decir, la oposición yo / tú se manifiesta en la oposición:

$$
\begin{array}{ccc}
\begin{array}{c}
\text { cualificaciones } \\
\text { del tú }
\end{array} & / & \begin{array}{c}
\text { funciones } \\
\text { del yo }
\end{array}
\end{array}
$$

Esta oposición, a su vez, remite al contraste:

$$
\text { pasividad / actividad }
$$

con que pueden calificarse al tú y al yo respectivamente.

El inventario lexemático y contextual del yo define su quehacer, no su ser, como en el caso del tú.

El tú "es" el objeto de deseo que atrae al yo, y como tal se califica en su esencia y en su existencia ("amor", "tersura", "luminosidad", "calor", "Ilamado", "receptividad"): 


\author{
Es "cráter que me convoca" \\ El yo "actúa" para conseguir ese objeto. Dice: \\ "me arrojo" \\ "quiero vivir en el fuego"
}

Aparece entonces investido de semas funcionales contrastantes: deseo/renuncia, amor/dolor, vi$\mathrm{da} /$ muerte.

Aunque en apariencia el yo manifiesta series de oposiciones binarias en su actuar, vemos que en realidad hay una identificación de contrarios, explicables por la concepción dialéctica del amor aleixandrino, que ya señalamos en el apartado 2, págs. 22-23):

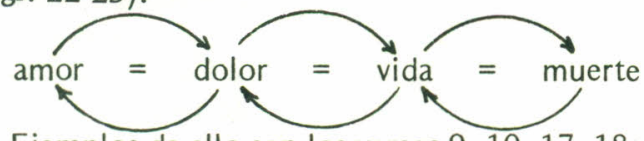

Ejemplos de ello son los versos 9, 10, 17, 18:

"Muero porque me arrojo, porque quiero vivir porque quiero vivir en el fuego..."

"Quiero amor o la muerte, quiero morir del todo quiero ser tú, tu sangre, esa lava rugiente..."

La isotopía erótica, entonces, si bien se configura a partir del yo-tú como contrarios (lo activo/lo pasivo; lo motor/lo receptivo) que se fusionan, fundamenta su existencia tanto en esa oposición de ellos, cuanto en la unión de ambos, que es vida y muerte, amor y dolor, deseo y renuncia:

9-10 "muero porque... quiero vivir en el fuego"

17 "Quiero amor o la muerte, quiero morir del todo

18 quiero ser tú, tu sangre..."

Podemos decir entonces que esta isotopía descansa en series binarias (cuyos extremos son el yo y el tú), que se pueden enunciar así:

Deseo

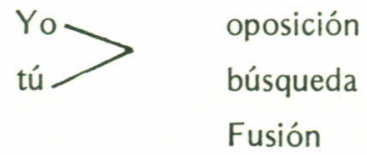

Por otra parte en esta isotopía los recursos de la metáfora y la sinécdoque o metonimia sirven para expresar la unión amorosa, la cual es vida/muerte, amor/dolor, deseo/renuncia:
21 "este beso en tus labios como una lenta espina

24 es todavía unas manos, un repasar de tu crujiente pelo"

11 "El caliente aliento que... quema y dora mis labios desde un fondo"

15 "el hondo clamor de tus entrañas

16 donde muero y renuncio a vivir para siempre"

7 "cráter que me convoca con su música íntima con esa indescifrable llamada de tus dientes"

\subsection{Isotopía telúrica}

Se fundamenta a partir de la oposición binaria originada también, como la isotopía anterior, en los lexemas yo/tú.

El tú es el actante-objeto telúrico con cualificaciones cósmicas, contenidas en los lexemas que remiten a la materialidad elemental ("cráter", "lava", "fuego", "luz").

El yo es el actante-sujeto que tiene el investimento semántico de la humanidad ("Iabios", "cuello", "rostro").

La oposición básica remite entonces al cosmos como principio fundamental, cuyos dos extremos serán el yo y el tú, lo humano y lo telúrico:

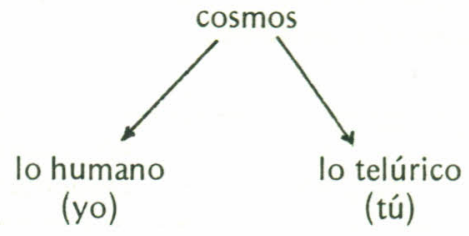

En esta isotopía se efectúa un proceso de metamorfosis cósmica: lo humano, concretizado en el yo, pasa a ser materia, cosmos, por la fusión con el tú, expresada, metafóricamente con el amor (21).

Decíamos anteriormente (apartado 2, pág. 103) que esta isotopía conduce al plano evocado, metafórico de la unión yo/tú. En este plano el amor no es concebido como el erotismo humano, sino como "la fuerza cósmica que aglutina los elementos y los condiciona avasalladoramente" (22).

El inventario lexemático en el cual se apoya la isotopía se reduce a las unidades lingüísticas que llevan los semas "materialidad", "vitalidad", "teluricidad", "unión", "luminosidad", "calor", "color", "profundidad", "eternidad", con sus contrarios.

El cuadro número cuatro, contiene el inventario lexemático y sémico de esta isotopía. 
CUADRO No. 4

INVENTARIO LEXEMATICO

DE LA ISOTOPIA TELURICA

Semas

Manifestación

lexemática

Mundo, Región, Todo, Mar.

Entrañas, fondo, hondo.

Límites, extremos

Pájaros, música, llamada, convoca, clamor rugiente.

Fugitivos, fluye, aire, aliento

Diamante, rubí, sol, brillo, deslumbra

Cráter, lava, fuego, caliente, quema, dora enrojecido, purpúrea, crujiente, crepitar.

Muero, morir, muerte, moral, destruir, renuncio, espina, espada, vengadora, amenaza, arrojo, olvido nunca, lenta.

Vivir, vida, amor, siempre, hermoso, bello, unidad 
De acuerdo con el inventario lexemático y sémico, hay series de oposiciones que remiten, por un lado, a la materialidad elemental, telúrica, y por otro, a la humanidad.

Veamos algunas:

\section{Vitalidad / No vitalidad}

"El hondo clamor de tus entrañas" / "Muero porque me arrojo" tu purpúrea vida / "renuncio a vivir para siempre"

\section{Eternidad / fugacidad}

"la región donde nada se olvida / "cuerpo feliz que fluye"

Teluricidad / Humanidad

"cráter" / "forma externa"

"lava rugiente" / "sangre"

Profundidad / altitud

"cráter que me convoca" / graciosos pájaros volando"

"hondo clamor" / "Luz", "sol"

La isotopía descansa en elementos telúricos fundamentales, primarios, que remiten al origen del cosmos.

Jon los cuatro elementos que los filósofos presocráticos definían como originarios de la vida: agua ("mar") aire ("aliento", "aire"), tierra ("mundo") y fuego ("calor", "lava", "sol", "fuego").

Es con esos elementos con los cuales se identifica y se materializa el tú.. Hacia ellos, entonces, se dirige el yo, en ju inexorable proceso de unificación o regreso a la materia (23):

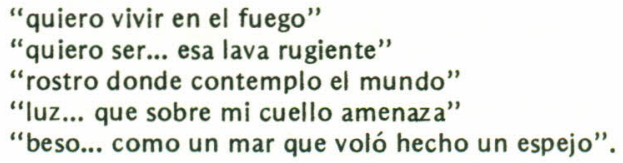

Las oposiciones semánticas que se derivan de esta segunda lectura también, como en la isotopía erótica, se fusionan: la vida es muerte, y lo humano es cosmos, materia.

\subsection{Isotopía de la Unidad}

Es la isotopía englobante del poema, la que fusiona y separa el plano erótico y el telúrico, lo individual y lo universal.

Se configura, entonces, con base en la oposición/fusión de las isotopías ya estudiadas.

El elemento común a ellas, y que permite la doble lectura es el "tú", mujer y cosmos, objeto de deseo y término de la fusión del yo-sujeto.

El cuadro número 5 explica la estructura semántica de la composición poética:

CUADRO No. 5

ESTRUCTURA SEMANTICA DE "UNIDAD EN ELLA"

ISOTOPIA DE LA UNIDAD

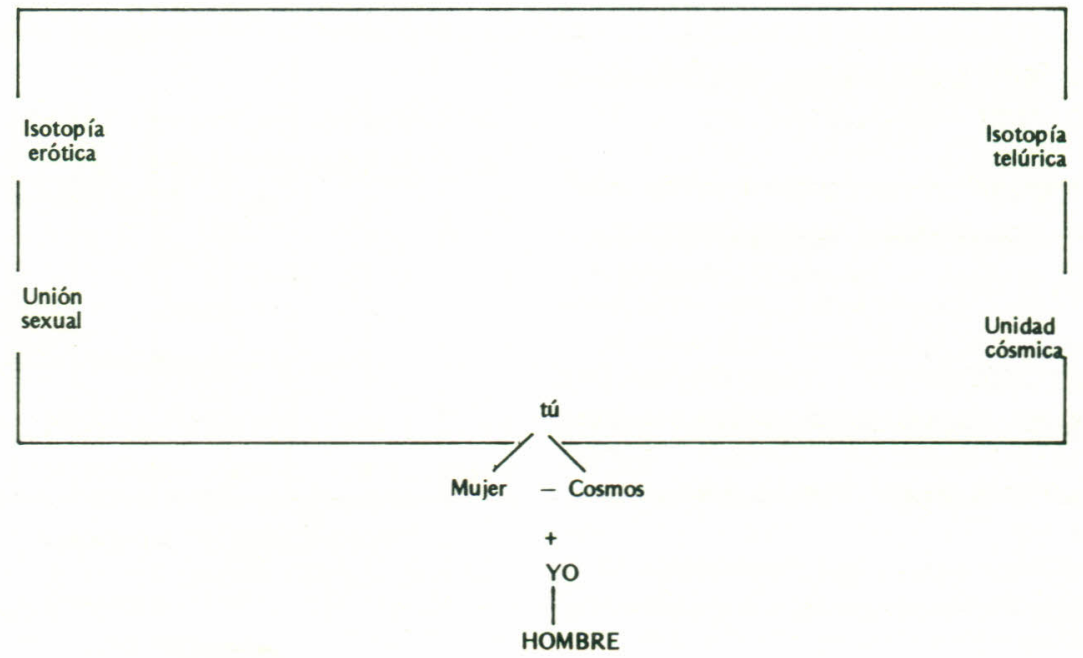


La unión sexual de la isotopía erótica se identifica y fusiona con la unidad cósmica a la cual tiende el yo en la isotopía telúrica. Tenemos así una unidad que el poema define en su título y en su último verso:

\section{UNIDAD EN ELLA}

\section{UNIDAD DE ESTE MUNDO}

La "unidad en ella" es el acto individual del amor humano. La "unidad de este mundo" es el proceso universalizador del regreso al cosmos.

Como ya dijimos es mediante el tú (mujer y cosmos) que se efectúa la unidad. $Y$ es el amor el principio motor de la fusión:

"teñido del amor,

enrojecido el rostro por tu purpúrea vida

... muero y renuncio a vivir para siempre"

Luis Felipe Vivanco al referirse a la poesía de Aleixandre afirma: "La poesía de Aleixandre es un largo esfuerzo hacia la luz, pero a través de una palabra pasional y telúrica. La pasión es la que le da unidad vital o existencial al poema y la tierra, la que le da totalidad o realidad total.

El hombre ya no es una realidad entre alma y cúerpo... sino su espíritu pasional unitario, y concretado en ese ímpetu, se va a incorporar a la totalidad del universo... En Aleixandre... en vez de incorporarse el mundo a un alma contemplativa, va a ser la pasión vital del poeta la que se incorpora al mundo, hasta identificarse o fundirse con él (24).

Con estas palabras confirmamos la descripción semántica que hicimos del poema.

\section{Los planos fónico, sintáctico y morfológico y su relación con lo semántico}

\subsection{El "coupling" como instrumento de análi-} sis

La descripción del plano semántico no conduce por sí misma a revelar el misterio de la esencia de lo poético. Para la comprensión total del poema y la captación de su vivencia, organización y estructura, es necesario ana'izar también otros planos, mediante los cuales se crea el mensaje poético.

Es por ello que utilizando la noción de "coupling" (25) trataremos de relacionar aspectos fónicos, sintácticos y morfológicos cc. l lo semántico y captar así la totalidad que constituye el poema.
Hemos de partir del principio, enunciado por Levin y acogido por Fernando Lázaro, según el cual el poema "genera su propio código, cuyo único mensaje es el poema" (26).

Así pues, veremos que el código utilizado en el poema es muy restringido y que se estructura con base en series de equivalencias semánticas y fónicas entre las palabras. Estas, a su vez, al ocupar posiciones equivalentes en el sintagma, conducen al "apareamiento poético, emparejamiento que viene a fundir la forma y el contenido del poema" (27).

El "coupling" entonces, se produce entre signos que son equivalentes en lo formal, lo semántico y lo posicional sintáctico.

En cuanto a lo semántico debemos recordar que la equivalencia se da no sólo cuando hay similitud, sino también cuando hay disimilitud.

Por otra parte, las posiciones pueden ser comparables o paralelas. Son comparables si se dan en palabras con idéntica función gramatical con respecto a un término. Son paralelas, aquellas en las que los términos son equivalentes porque desempeñan la misma función en oraciones distintas (28).

El poema "Unidad en ella" está constituido por una tenue red de equivalencias que permiten demostrar el alto grado de "cohesión poética" (29) que tienen entre sí los elementos formales y del contenido de su lenguaje.

Esa cohesión nos permite reafirmar, además, el principio de permanencia del mensaje (30), característico de la poesía.

Analizaremos las equivalencias significativas del texto para reafirmar el sentido hallado en el poema con la descripción semántica de sus planos isotópi$\cos$.

El poema consta de cinco períodos sintácticos divididos así:

I: estrofas 1 y 2 (versos 1 al 8$)$

II: estrofa 3 (versos 9 al 12)

III: estrofa 4 (versos 13 al 16)

IV: estrofa 5 (versos 17 al 20)

V: estrofa 6 (versos 21 al 27)

La estructura sintagmática repite, en esas partes, series de "apareamientos" (31) por posición comparable o paralela, los cuales intensifican los aspectos semánticos ya analizados.

\subsection{Primer período sintáctico.}

Como ya lo señalamos antes (pág. 4) las estrofas 1 y 2 califican al tú con una serie encadenada de 
adjetivaciones. Hay una manifiesta economía sintáctica, pues el sujeto y verbo ("tú eres") aparecen elípticos, y se constituye el período con un recargo de predicados nominales referidos al tú (32).

Los predicados constituyen series de apareamientos que están hechos con la misma estructura sintáctica (presente en el texto o su equivalente transformacional): PREDICADO NOMINAL: SUJ + ORACION SUBORDINADA ADJETIVA.

En el cuadro número 6 se señalan estas posiciones sintácticas.

CUADRO No. 6

ESQUEMA DEL PRIMER PERIODU SINTACTICO

VERSOS POSICIONES SINTACTICAS

\begin{tabular}{|c|c|c|c|c|}
\hline & SUJETO & VERBO & \multicolumn{2}{|r|}{ PREDICADO NOMINAL } \\
\hline & \multirow{4}{*}{ (Tú) } & \multirow{3}{*}{ (Eres) } & \multicolumn{2}{|c|}{ sujeto $\quad$ Oración Subordinada } \\
\hline 1 & & & Cuerpo feliz & que fluye entre mis manos \\
\hline 2 & & & Rostro amado & $\begin{array}{l}\text { donde contemplo el mundo } \\
\text { (que refleja) }\end{array}$ \\
\hline 3 & & & & $\begin{array}{l}\text { donde graciosos pájaros se copian } \\
\text { fugitivos... } \\
\text { (que semejan graciosos pájaros fugitivos) }\end{array}$ \\
\hline 6 & $\begin{array}{l}\text { tu forma } \\
\text { externa }\end{array}$ & (es) & $\begin{array}{l}\text { diamante } \\
\text { rubí duro } \\
\text { brillo de un sol }\end{array}$ & que deslumbra entre mis manos \\
\hline $\begin{array}{l}7 \\
8\end{array}$ & & & cráter & $\begin{array}{r}\text { que me convoca con su música íntima } \\
\text { con esa indescrifrable } \\
\text { llamada de tus dientes }\end{array}$ \\
\hline
\end{tabular}

NOTA: Las palabras o sintagmas entre paréntesis son elipsis del texto o transformaciones del mismo.

Los predicados nominales del tú responden a “couplings" equivalentes por posición.

Los versos 1 y 2 tienen equivalencia por posición comparable respecto a (eres):

(eres) cuerpo feliz que fluye entre mis manos rostro amado (que refleja) el mundo

Hay en ellos, además de la equivalencia sintáctica, también morfológica:

$\begin{array}{lllll}\text { SUST } & \text { ADJ / } & \text { RELATIVO } & \text { / } & \text { VERBO } \\ \text { cuerpo } & \text { feliz } & \text { que } & \text { fluye } \\ \text { rostro } & \text { amado } & \text { que } & \text { refleja }\end{array}$

Asimismo hay equivalencia semántica:

$$
\begin{array}{llll}
\text { cuerpo } & \text { feliz } / & \text { que fluye } \\
\text { rostro } & / & \text { amado / } & \text { que refleja }
\end{array}
$$

En lo fonológico la aliteración en "f" ayuda al movimiento plácido del tú-mujer hacia el paso al tú-cosmos.

Los versos 5, 6 y 7 presentan también equivalencias por posición comparable. Está constituidas igualmente por predicaciones nominales, esta vez del tú como "forma externa", que es cosmos, materia telúrica: 
tu forma externa (es) diamante

\section{rubí/duro}

brillo/ de sol / que deslumbra

cráter / que me convo-

$\mathrm{ca}$

Hay asimismo equivalencias morfológicas que repiten la estructura ya dada en los versos 1 y 2 :

\section{VERSO/ SUST./ AD J / RELATIVO/VERBO}

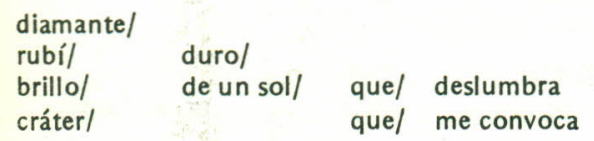

Estas conducen a la equivalencia semántica por identificación cualitativa:

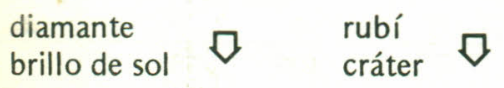

En lo fonológico hay aliteración de sonidos, que refuerzan lo semántico:

6. brillo de un sol que deslumbra

7. cráter que me convoca con su música íntima...

Asimismo la acentuación esdrújula incide para hacer equivalentes lo fonológico y lo semántico en:

3. graciosos pájaros

7. música íntima

Hay finalmente, en los versos 7 y 8 equivalencias por posición comparable, en lo sintáctico, morfológico y semántico:

$$
\text { V / prep / adj/ sust/ adj. }
$$

convoca

$$
\begin{array}{lll}
\text { con su música íntima } \\
\text { con/ esa/ } & \begin{array}{l}
\text { Ilamada/indescrifrable/ } \\
\text { de tus dientes }
\end{array}
\end{array}
$$

Los versos 1 y 6 presentan también una equivalencia por posición paralela, que engloba los niveles sintáctico, morfológico, fónico y semántico:

1. Cuerpo/ feliz/ que / fluye/ entre/ mis/manos

6. brillo/ de un sol/ que/ deslumbra/ entre / mis / manos

Resumiendo las equivalencias de este primer período, podemos decir que lo sintáctico, lo morfológico y lo fonológico inciden de manera muy clara en lo semántico, es decir hay una estructura sintagmática y fónica en las dos estrofas que remite a la cualificación del tú como mujer-cosmos.

Por un proceso de equivalencias ese tú es:

cuerpo/feliz

rostro/amado

diamante

rubí/duro

brillo/de un sol

cráter

El tú además, es un ser "antropo-cósmico":

que/fluye/entre mis manos

/que/refleja/graciosos pájaros fugitivos

que/deslumbra/entre mis manos

que/me convoca/con su música íntima

con esa indescifrable llamada de tus dientes.

Con el análisis de los otros períodos sintácticos del poema veremos que hay otras series de equivalencias entre elementos de las diferentes partes.

\subsection{Segundo período sintáctico}

Está compuesto por dos partes, ligadas por el verbo principal "muero" y por la conjunción "porque". El cuadro $\mathrm{N}^{\circ} 7$ recoge el período. 
CUADRO No. 7

ESQUEMA DEL SEGUNDU PERIODO SINTACTICO (*)

VERSOS POSICIONES SINTACTICAS

\begin{tabular}{|c|c|c|c|c|c|c|}
\hline & VERBO PRINC. & CONJUNCION & VERBO & C.D. & & C.C. \\
\hline $\begin{array}{l}9 \\
9 \\
10\end{array}$ & Muero & $\begin{array}{l}\text { porque } \\
\text { porque } \\
\text { porque }\end{array}$ & $\begin{array}{l}\text { arrojo } \\
\text { quiero } \\
\text { quiero }\end{array}$ & $\begin{array}{l}\text { me } \\
\text { morir } \\
\text { vivir }\end{array}$ & & en el fuego \\
\hline & $\begin{array}{l}\text { VERBO } \\
\text { PRINC. }\end{array}$ & CONJUNCION & SUJETO & NEG. & $\begin{array}{l}\text { VER } \\
\text { BO }\end{array}$ & PREDICADO \\
\hline $\begin{array}{l}10-11 \\
11 \\
12 \\
12\end{array}$ & (Muero) & Porque & $\begin{array}{l}\text { este aire de } \\
\text { afuera }\end{array}$ & No & $\begin{array}{l}\text { es } \\
\text { (es) }\end{array}$ & $\begin{array}{l}\text { Mío } \\
\text { El caliente aliento } \\
\text { que quema } \\
\text { (que) dora mis } \\
\text { labios }\end{array}$ \\
\hline
\end{tabular}

(*) Este período estructura sus versos siguiendo dos modelos: uno en los versos 9-10 y otro en los versos 10-11 y 12. De ahí que presentemos el esquema en dos partes.

Mediante tres series de acciones equivalentes ofrece el primer indicio de metamorfosis o fusión del yo con el tú cósmico. Veamos:

$$
\begin{aligned}
& \text { 9. Muero/ porque/ arrojo/ me } \\
& \text { 9. porque/ quiero/ morir } \\
& \text { 10. porque/ quiero/ vivir en el }
\end{aligned}
$$

Hay equivalencias sintácticas, morfológicas y semánticas en los versos. Son equivalencias por posición comparable y por contenido entre:

$$
\nabla \begin{aligned}
& \text { arrojo } \\
& \text { quiero } \\
& \quad \square \text { vivir/en el fuego }
\end{aligned}
$$

Los versos 10 al 12 contienen otro aspecto de la metamorfosis o fusión. En lo formal se manifiesta mediante dos oraciones cualificativas, que hacen equivalencias.
Los versos dicen:

Muero / porque

este aire de afuera/no/es/mío sino/(es)/ el caliente aliento

Hay coupling semántico, morfológico, sintáctico y fónico:

$\nabla \begin{array}{ll}\text { laire/ de afuera / mío } \\ \text { aliento/ } \\ \text { caliente }\end{array}$

El "aliento" del tú, además, refuerza sus cualificaciones con dos subordinadas adjetivas que son también, equivalentes:

caliente aliento/que/quema/

y /dora / mis labios desde un fondo 
Los verbos "quema" y "dora" tienen equivalencias por identidad semántica y funcional.

El sonido aliterativo "ka", "ke" contribuye a reafirmar la ola cálida que envuelve la unión yo/tú y su integración posterior.

\subsection{Tercer período sintáctico}

El proceso de fusión amorosa yo/tú y la metamorfosis cósmica avanzan en este período, apoyados en series de equivalencias.

El cuadro número ocho contiene el esquema de las posiciones sintácticas presentes en cada verso:

CUADRO No. 8

ESQUEMA DEL TERCER PERIODO SINTACTICO

\section{VERSOS POSICIONES SINTACTICAS}

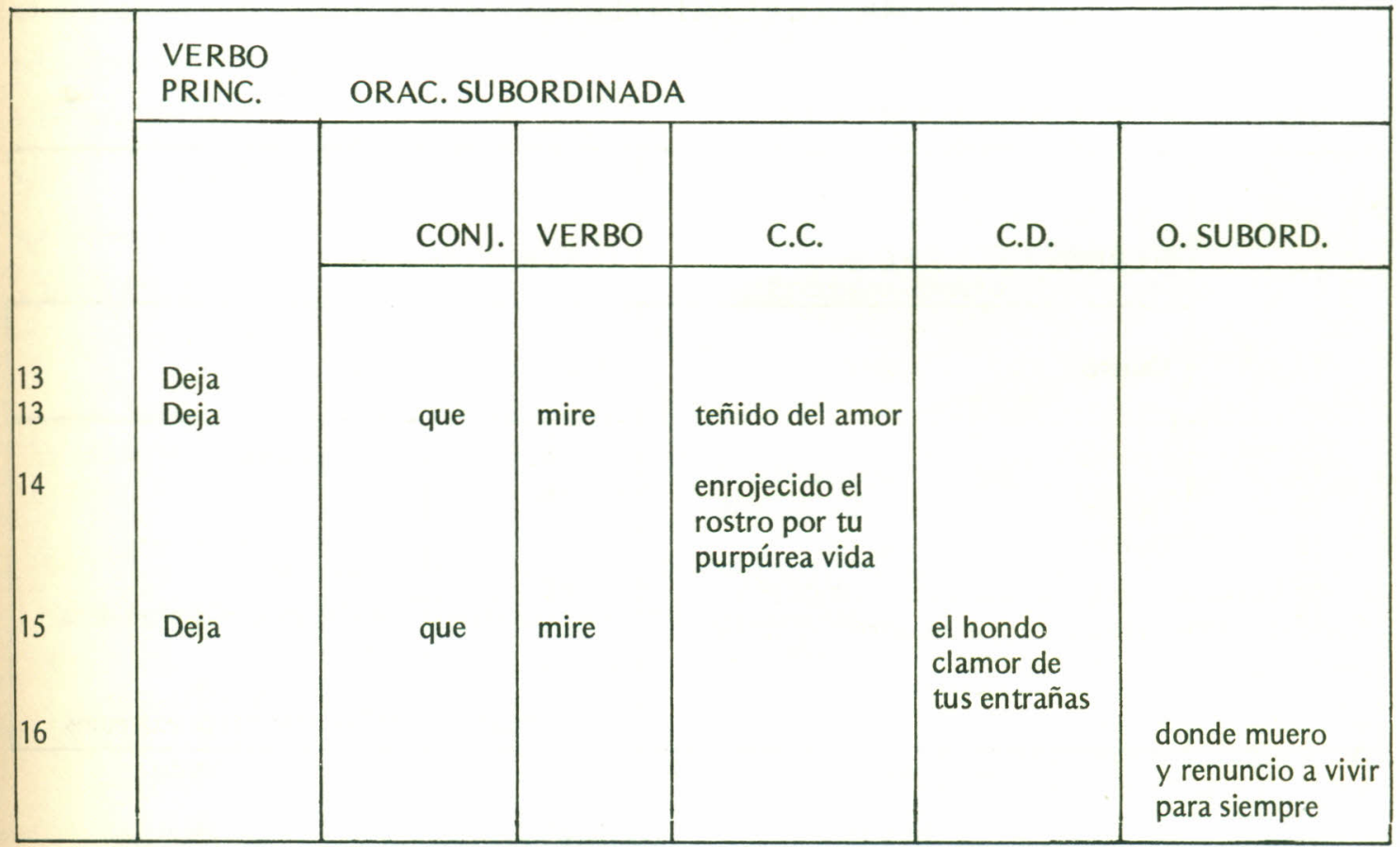

Del esquema se extraen dos series de equivalencias, originadas la primera en la posición de complemento circunstancial de la subordinada "que mire", dependiente del imperativo "deja". La equivalencia es por posición comparable:

deja/que mire/teñido/del amor enrojecido/por tu purpúrea vida/el rostro... co:

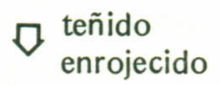

Ambos son participios pasivos con identidad semántica.

$$
\square \text { purpúrea vida }
$$

Son sustantivos equivalentes en su esencia, según el poema. 
La segunda serie de equivalencias está dada por la doble subordinación que califica al tú:

hondo clamor de tus entrañas/donde/muero y/renuncio a vivir para siempre.

"Muero" y "renuncio a vivir para siempre" son equivalentes por posición comparable, por equivalencia semántica y por su morfología.

La muerie individual del yo propicia la unión cósmica, la metamorfosis, que se anuncia también en los complementos circunstanciales:

teñido del amor

enrojecido por tu purpúrea vida

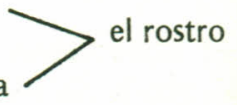

\subsection{Cuarto período sintáctico.}

En este período es donde se manifiesta de forma más clara el deseo de fusión y metamorfosis del yo.

El cuadro número 9 contiene el esquema de las posiciones sintácticas de este período.

CUADRO No. ㅇ

ESQUEMA DEL CUARTO PERIODO SINTACTICO

VERSOS POSICIONES SINTACTICAS

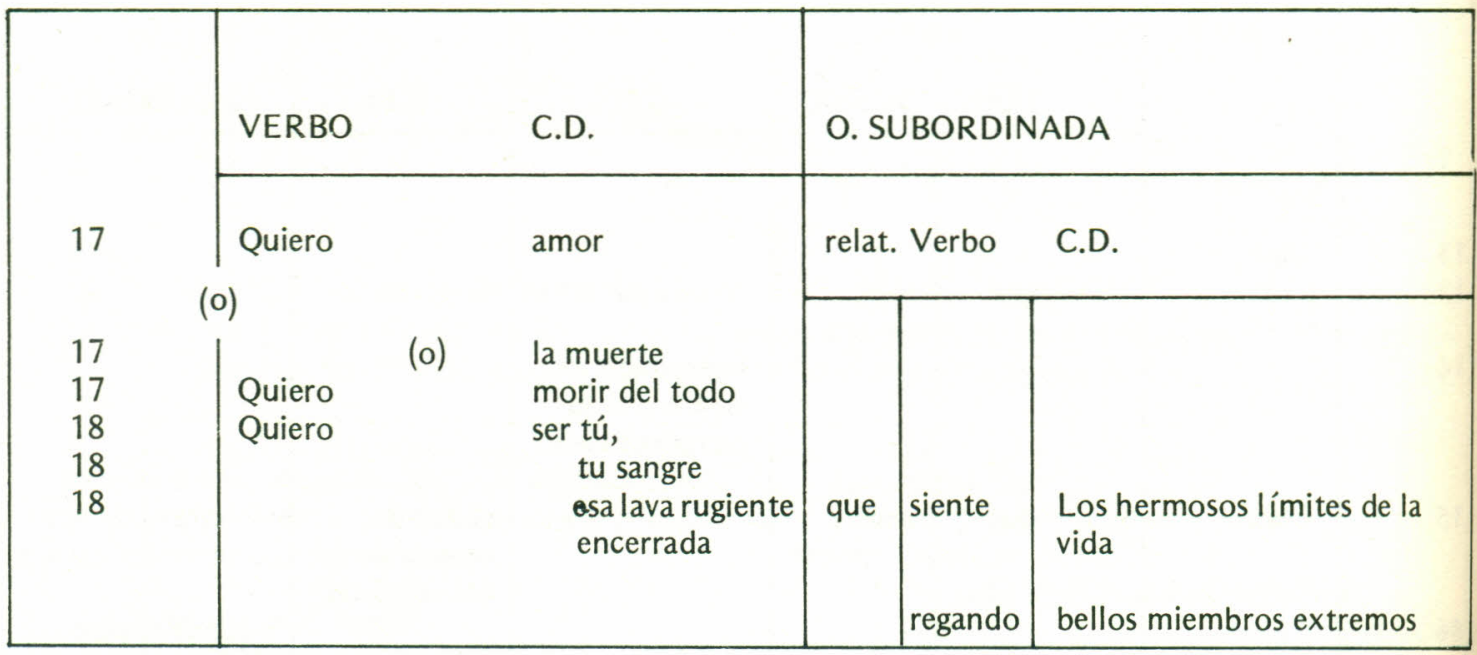

Los versos 17 y 18 reiteran la forma verbal "quiero" de la que dependen cuatro complementos directos, que son equivalentes por posición comparable entre sí:

$\begin{array}{ll}\text { quiero } / & \text { amor } \\ & \text { muerte } \\ & \text { morir } \\ & \text { ser/tú/tu sangre/ }\end{array}$

Morfológicamente también son equivalentes por su calidad de sustantivos. Además, se organizan en parejas.
NOMBRES: amor, muerte DERIVADOS VERBALES: morir, ser

La equivalencia se proyecta en el plano semántico, donde hay coupling por identidad y disimilitud a la vez. Esta equivalencia confirma la concepción del amor en el poema.

A partir del verso 18 hay, además otras equiva. lencias, derivadas de las cualificaciones atribuidas al tú, mujer y cosmos.

En primer lugar, ese "tú" es: 
tú

tu sangre

lava rugiente

encerrada

regando

Hay equivalencia posicional entre "sangre" y "lava, que son además, semánticamente equivalentes, pues se refieren a los dos planos del tú, mujer y cosmos.

Los derivados verbales "rugiente" "encerrada" y "regando" también presentan equivalencias sintácticas y morfológicas, reforzadas por la equivalencia fónica que señala la aliteración en la vibrante "r".

Veremos que también son equivalentes semánticamente, sobre todo en relación con elementos de otros períodos que califican al tú/cosmos:

v. 1 Cuerpo "que fluye"

v. 19 lava "encerrada"

v. 19 "regando"

v. 7 cráter con "música íntima"

v. 18 lava "rugiente"
Por otra parte, el período cuarto contiene una subordinación adjetiva de la cual se derivan otras equivalencias:

$18-20$

lava/rugiente/que/siente/los hermosos/límites/ de la vida

19-20 encerrada

regando /bellos/ miembros/ extremos

"Rugiente" y "siente" tienen terminación idéntica con aliteración en la sílaba acentuada que las hace equivalentes.

Hay también otras equivalencias claras entre:

19 hermosos/límites/de la vida
20 bellos/miembros/extremos

La posición sintáctica, lo morfológico y lo semántico ofrecen en estos elementos una equivalencia total.

\subsection{Quinto período sintáctico}

Las equivalencias en este período derivan de la posición sintáctica "predicado nominal".

El cuadro número 10 así lo señala:

CUADRO No. 10

ESQUEMA DEL QUINTO PERIODO SINTACTICO

VERSOS POSICIONES SINTACTICAS

\begin{tabular}{|c|c|c|c|c|c|c|}
\hline & SUJETO & VERBO & ADV. & CONJUNCION & PREDICADO NOMINAL & C.C. \\
\hline 21 & este beso & (es) & como & & una lenta espina & en tus labios \\
\hline 22 & & & como & & $\begin{array}{l}\text { un mar que voló hecho } \\
\text { un espejo }\end{array}$ & \\
\hline 23 & & & como & & el brillo en un ala & \\
\hline 24 & & es & todavía & & unas manos & \\
\hline 24 & & & & & $\begin{array}{l}\text { un repasar de tu crijiente } \\
\text { pelo }\end{array}$ & \\
\hline 25 & & & & & $\begin{array}{l}\text { un crepitar de la luz } \\
\text { vengadora }\end{array}$ & \\
\hline 26 & & & & & Luz & \\
\hline 26 & & & & 0 & $\begin{array}{l}\text { espada mortal/que } \\
\text { sobre mi cuello amenaza. }\end{array}$ & \\
\hline 27 & & & & pero & $\begin{array}{l}\text { /que nunca } \\
\text { podrá destruir la } \\
\text { unidad de este mundo. }\end{array}$ & \\
\hline
\end{tabular}


Es en esa posición en la cual las cualificaciones que fusionan el acto sexual y la unión cósmica manifiestan sus semejanzas.

Todo el período es la reiteración de series de cualificaciones, introducidas por dos adverbios: "como" y "todavía".

Beso (es) como espina/lenta
mar/que voló hecho un espejo
brillo/de una ala
manos
repasar/de tu crujiente pelo
crepitar/de la luz vengadora
luz
espada/mortal
/que sobre mi cuello amena-
za
/ que nunca podrá destruir
la unidad de este mundo

Las cualificaciones predicativas son todas equivalentes por posición comparable, pero además por equivalencia morfológica (son sustantivos). Hay también equivalencias semánticas. Veamos:

espina/lenta

mar/que voló

brillo/de un ala

Las adjetivaciones son equivalentes por disimilitud. Remiten a la ambigüedad, ya explicitada en versos anteriores, de la fugacidad y la permanencia de la vida, el amor, la muerte y el dolor.

En los versos 24 y 25 :

repasar/de tu crujiente pelo

crepitar/de la luz vengadora

Hay equivalencia posicional y morfológica en los infinitivos, acrecentada por la aliteración $\mathrm{cr}$ común a ambos versos.

El chasquido "cr" además, se acentúa por la equivalencia semántica:

crujier,te

crepitar

la cual remite a otros elementos morfológicos del poema, en los cuales se da asimismo la identidad del ardor del fuego:
v. 18 rugiente
v. 15 clamor

También hay equivalencias entre:

$$
\begin{aligned}
& \text { luz/vengadora } \\
& \text { espada/mortal }
\end{aligned}
$$

Ambas remiten a la unión erótica y cósmica como la fusión entre amor y dolor, vida y muerte, contenidos en sus matices semánticos:

\section{Beso es $\square$ luz/vengadora
espada/mortal}

La espada, además, concebida como instrumento de amor:

amenaza/mi cuello nunca podrá destruir/la unidad de este mundo

Es decir, ayuda a borrar la individualidad al conseguir la fusión yo/tú, es instrumento de muerte. Pero a la vez conserva la unidad yo/cosmos, por lo que es instrumento de vida, al permitir al yo integrarse a sus orígenes primarios.

Hay, pues, equivalencias notables en la estructura sintáctica, morfológica y semántica de las oraciones subordinadas referidas a "espada".

\subsection{Equivalencias entre períodos sintácticos diferentes}

Una vez realizado el análisis de cada uno de los períodos sintácticos establecidos en el poema, hemos de analizar aquellos apareamientos significativos entre partes de diferentes períodos, para corroborar así, la indiscutible cohesión y unidad poética que manifiesta "Unidad en ella".

Es imprescindible hacer notar, como elemento estructurante significativo del poema el uso reiterado de la adjetivación en todas sus formas:

1. Como adjetivo calificativo común, que hace equivalencia posicional y semántica:

$\begin{array}{llll}\text { cuerpo feliz } & \text { espada } & \text { mortal } \\ \text { rostro amado luz } & \text { vengadora }\end{array}$

2. Como participo activo en función adjetiva:

caliente aliento

rugiente lava

crujiente pelo 
Además de la posición paralela hay equivalencia fónica y semántica a la vez, que remite al fuego como principio y fin de la unión cósmica y de la unión amorosa.

3. Como cualificaciones expresadas por adjetivación cruzada, que también crean equivalencias sintácticas, morfológicas $y$, por supuesto semánticas:

"hondo/clamor/de tus entrañas"

"indescriptible/llamada/de tus dientes".

"bellos/miembros/extremos

hermosos/límites/de la vida"

En los dos ejemplos, la adjetivación nos conduce por los caminos de la ambigüedad mujer/cosmos y de la dualidad fin/principio.

4. Como oración subordinada adjetiva el recurso cualificativo se ve enriquecido grandemente. Todo el poema constituye una pictórica descripción del tú, mujer y cosmos, y de la unión erótico-telúrica mediante la cual se vuelve a los orĭgenes del mundo.

Veamos ejemplos:

cuerpo feliz/que/fluye

brillo de un sol/que/deslumbra

caliente aliento/que/quema

lava rugiente/que/siente

espada mortal/que/amenaza

cráter/que/me convoca

Así pues, la subordinación adjetiva también plasma series de equivalencias sintácticas, morfológicas, fónicas y semánticas.
Los versos 1, 22, 3 y 23 presentan equivalencias importantes que refuerzan la idea de metamorfosis cósmica, de paso de lo humano a lo telúrico.

Esta transmutación se fundamenta en la constante fluidez o cambio de la materia y en la concepción del ser humano como reflejo del cosmos.

Veamos los versos y sus equivalencias:

"cuerpo que fluye entre mis manos

"rostro donde graciosos pájaros, se copian fugitivos"

"mar que voló hecho un espejo"

"rostro donde contemplo el mundo"

Analicemos ahora las equivalencias semánticas obtenidas de las cualificaciones del tú.

La mujer/tierra del poema es:

cuerpo/cráter

sangre/lava rugiente

hondo clamor de tus entrañas/caliente aliento

bellos miembros extremos/hermosos límites de la vida

Todos los elementos conducen a la identidad última del tú-mujer en el tú-cosmos.

La transmutación de lo humano en cosmos se realizará a través del elemento vital: la sangre, en un proceso circular que podríamos enunciar así:

"tu sangre" $\rightarrow$ "aire de afuera" $\rightarrow$ caliente aliento" $\uparrow$ beso".

\section{CONCLUSIONES} bar:

El análisis realizado nos ha permitido compro-

5.1. La motivación exhaustiva del signo literario que se hace patente en todas y cada una de las partes de la red significativa que constituye el mensaje poético.

5.2. La interdependencia de los niveles componenciales del discurso lírico y su estructuración era una unidad significativa.

5.3. La articulación compleja del plano semántico del poema y su manifestación biisotópi-

ca en lo humano y lo cósmico, que se co-funden en una misma esencia erótico-telúrica.

5.4. La estructura sintáctica del poema como engaste de lo fónico, lo semántico y lo morfológico.

5.5. La utilidad de los planteamientos teóricos de Levin y Greimas, que permiten su adaptación al análisis de este poema concreto.

5.6. La necesidad de tener presentes, al analizar el discurso lírico, dos ideas. La de Levin de que "cada poema genera su propio código 
cuyo único mensaje es el poema" (33). Y la de Jakobson de que "todo elemento verbal se convierte, en poesía, en figura del discurso poético" (34).

\section{NOTAS BIBLIOGRAFICAS}

(1) Guillermo Barzuna P. "Pautas para un análisis semiológico de la escritura poética”. En Káñina (vol. III, No. 1 Ene-jun. 1979, San José) p. 118.

(2) Véase al respecto:

Jenaro Talens y otros. Elementos para una semiótica del texto artístico (Madrid, Cátedra, 1978) p. 69.

Román Jakobson dice: "la poeticidad no consiste en añadir una ornamentación retórica al discurso, sino una revalorización total del discurso de cualesquiera de sus componentes". En: "Lingüística y poética". Ensayos de lingüistica General. (Barcelona, Seix Barral, 1975) p. 394.

(3) Gerard Genette. "Lenguaje poético, poética del lenguaje". En: Roland Barthes y otros: Estructuralismo y literatura. Buenos Aires, Nueva Visión, 1972) p. 73.

(4) Román Jakobson. Op. cit. p. 385.

(5) Especialmente véase: A Greimas: Semántica estructural. (Madrid, Gredos, 1966).

A. Greimas, M. Arrivé et. alt: Ensayos de Semiótica Poética (Barcelona, Planeta) 1976.

(6) Samuel Levin. Estructuras lingüisticas en la poesía. ( $2^{\circ}$ ed. Madrid, Cátedra, 1977).

(7) La isotopía consiste en un conjunto de ciertas categorías de significación redundantes en un texto. $F$. Rastier, siguiendo a Greimas la define como "toda iteración de una unidad lingüística". En: A.Greimas, M. Arrivé et alt. Op. cit. p. 110.

(8) Cfr. Marcelo Pagnini. Estructura literaria y método crítico. (Madrid, Cátedra, 1975) p. 165.

(9) Al respecto dice Greimas: "La aparición, en ciertos pasajes privilegiados del relato, de articulaciones complejas, bivalentes, provocará una lectura situada en varios planos isótopos a la vez". Semántica..., p. 149.

(10) Greimas, Op. cit. p. 41.

(11) Samuel Levin. Define al coupling como "la utilización de posiciones equivalentes como engaste de elementos fónicos o semánticos equivalentes". $O p$. cit. p. 49-50.

(12) Luis Felipe Vivanco afirma, con relación a la poesía de Aleixandre, que: "En el cuerpo, como grieta de bajada o de comunicación con el abismo del fondo, la pasión humana se confunde -o se co-funde- con las fuerzas terrestres más elementales". En: Introducción a la poesía española contemporánea. (I vol. Madrid, Guadarrama, 1974) p. 308.

(13) Carlos Bousoño considera la elisión del verbo principal como un recurso expresivo de Aleixandre que destaca la "economía sintáctica" y refuerza el acento como "más exclamativo o más confidencial". En: La poesía de Vicente Aleixandre". $\left(2^{\circ}\right.$ ed. Madrid, Gredos. 1968) p. 352-353.

(14) Carlos Bousoño define el acto erótico en Aleixandre como "la fuerza desintegradora del principio de individualización”. Op. cit. p. 70

(15) Leopoldo de Luis alude a esta influencia en Aleixandre, y dice al respecto: "En el fondo último de su ascendencia me parece ver esa destrucción que es amor en el recuerdo de la continua pugna amorodio moviendo al mundo de las teorías de Empédocles y los mecanicistas. Vicente frecuentó mucho a los presocráticos. Es esta una de las aportaciones aleixandrinas a la poesía actual|que han alcanzado repercusión mayor" En: Vicente Aleixandre (Madrid: Espesa, 1970 p. 155.

(16) Carlos Bousoño afirma: "Pero desde Ambito hasta Nacimiento Ultimo, el amor expresado por Aleixandre es según hemos visto, el amor-pasión, y más concretamente aún la acción misma erótica en su trascendencia metafísica, que consiste en relacionar al amante con lo absoluto telúrico.

Porque es el amor ante todo una acción que quebranta nuestros límites para unificarnos con el gran Todo...

...(La muerte) es la definitiva entrega la naturaleza amante, realidad última del universo, la muerte será vista como el supremo acto de la libertad de amor $y$ de vida.

Ingresar en la materia unitaria a través de la muerte será penetrar en una plenitud de vida superior. Es el "nacimiento último" a la verdadera existencia... Misticismo, pues; pero misticismo panteísta. Espiritualización de la materia, materia como perenne claridad, radioso lumen, cántico alegre que recibe al elegido, al muerto, destrozadas ya las individualizadoras fronteras". Op. cit. págs. 68, 72-73.

(17) Leopoldo de Luis dice: "el poeta se integra en el cosmos y canta la materia como única y total: la flora, la fauna, las montañas, el cielo, son una misma cosa material en la que el ser humano va ínsito. Su "nacimiento último" no es sino la culminación: 
el hombre, al fundirse a la tierra, a la materia cósmica, en la muerte, nace a la unidad total. Aquí hay, en cierto modo, una mística. Aleixandre se ha llamado a sí mismo "místico de la materia". Leopoldo de Luis, Op. cit. p. 155.

(18) En: Federico C. Sáinz de Robles. Historia y Antología de la poesía española. (Tomo I, Madrid, Aguilar, 19 ), pág. 691.

(19) La suspensión sémica ocurre en el discurso cuando en un lexema una oposición sémica cede paso a otra, que ubica el lexema en otro plano isotópico. Hay entonces suspensión de unos semas y sustitución por otros. Véase A. Greimas Semántica... p. 53.

(20) Carlos Bousoño dice, con respecto a la concepción del amor en Aleixandre: "El amor es para el primer Aleixandre destrucción, (quiero amor o la muerte) sobrecogedor aniquiliamiento de cada uno de los amantes que quieren ser el otro, enigma de una consumación en que la pareja busca unificarse rompiendo sus fronteras... Sólo después del acto erótico se recobra la forma, perdida antes por ese misterioso contacto de vida y muerte. Entonces parece como si cada uno de los que se han amado naciese del otro, espuma y Venus a un tiempo mismo. Carlos Bousoño, Op. cit. p. 70.

(21) Dámaso Alonso dice al respecto: "Trasmutación, amorosa co-fusión, todo es uno y la misma causa. Todo está en acto de erótica transmutación, aún en el mismo poeta, que llega a identificarse, a unirse -unión mística con el mundo que tan apasionadamente canta. $Y$ para cantarlo usará las formas del amor humano- según la tradición de la literatura mística... el amor humano siempre exhala aquí una proyección cósmica, las fuerzas telúricas terminan en ardientes enlaces humanos. He aquí, pues, el mito: las metamorfosis". En: Dámaso Alonso. Poetas españoles contemporáneos $\left(3^{\circ}\right.$ ed. Madrid, Gredos, 1969), p. 281.

(22) Leopoldo de Luis. Op. cit. p. 155.

(23) Afirma Carlos Bousoño, al referirse a la concepción del amor en Aleixandre: "Es el amor una fuerza que nos lleva a la generosa identificación con el objeto amado. Si ese objeto es el mundo tenderemos a vernos reflejados en él, y viceversa, a verle a él reflejado en nosotros. Nos converti- mos así en mundo, nos tornaremos en naturaleza, y a su vez, la naturaleza se unificará en una pura llama de amor que va de nosotros a la realidad circundante y vuelve a nuestro corazón, haciendo del entero universo un único fluido erótico, una única sustancia de la que participamos". Carlos Bousoño Op. cit. p. 67-68.

(24) Luis Felipe Vivanco Op. cit. págs. 311-312.

(25) El "coupling" es una estructura lingùística que "consiste en la colocación de elementos lingûísticos equivalentes en posiciones también equivalentes, o dicho a la inversa, en la utilización de posiciones equivalentes como engaste de elementos fónicos o semánticos equivalentes". Samuel Levin. Estructuras lingüísticas en la poesía. (Madrid, Cátedra. 1977). p. 49-50.

(26) Op. cit. p. 63.

(27) Levin, Op. cit. p. 64.

(28) Cfr. Ibid. p. 15.

(29) Cfr. Ibidem. p. 16.

(30) Levin, al referirse a la permanencia, dice: "En la poesía, tanto la forma como la impresión permanecen en la mente del lector... nos referimos aquí a su capacidad de ser fácilmente recordable... Dado que la permanencia se da en función de la unidad del texto, viene también explicada, en parte, por la estructura que hemos llamado apareamiento". Levin. Op. cit. p. 89.

(31) Así se ha traducido "coupling" al castellano.

(32) Recordemos que el texto del poema debe ser normalizado y que, según Levin "En la lectura de una pieza poética entran diversos ingredientes, entre ellos el conocimiento de esa parte de la gramática que es común al poeta y al lector... Así pues es legítimo introducir en el análisis del poema todo lo que podamos saber acerca de una construcción, y sus antecedentes de derivación transformacional". Levin. Op. cit. p. 1-82.

(33) Ibid, p. 63.

(34) Jakobson. Op. cit. p. 394. 


\section{BIBLIOGRAFIA}

Aleixandre, Vicente. Mis mejores poemas $3^{\circ}$ ed. Madrid, Gredos, 1968.

Alonso, Dámaso. Poetas españoles contemporáneos $3^{\circ}$ ed. Madrid, Gredos, 1969.

Barzuna P. Guillermo. "Pautas para un análisis semiológico de la escritura poética". En Káñina Vol. II No. 1, Ene-Jun 1979, San José.

Bousoño, Carlos. La poesía de Vicente Aleixandre $2^{\circ}$ ed. Madrid, Gredos. 1968.

Teoría de la expresión poética $5^{\circ}$ ed. 2 tomos, Madrid, Gredos, 1970.

Camacho R.; Jorge Andrés "Análisis de un poema de Antonio Machado: El limonero lánguido suspende...". En: Revista de Filología № 5, tomo III, Mayo 1977, p. 73-95.

Genette, Gerard. "Lenguaje poético, poética del lenguaje". En: Roland Barthes y otros: Estructuralismo y literatura. Buenos Aires, Nueva Visión, 1972.

Greimas, Julien A. Semántica estructural. Madrid Gredos, 1971. y Ensayos de Semiótica
A.A. V.V. Barcelona, Planeta, 1976.

Jakobson, Roman. Ensayos de lingüística General. Barcelona, Seix Barral, 1975.

\section{7.}

Ensayos de poética. México, I.C.E.

Levin, Samuel. Estructuras lingüísticas en la poesía $2^{\circ}$ ed. Madrid, Cátedra, 1977.

Luis, Leopoldo de, Vicente Aleixandre. Madrid, E.P.E.S.A. 1970.

Martínez Amador, Emilio. Diccionario gramatical y de dudas del idioma. Barcelona, Sopena, 1973.

Pagnini, Marcelo. Estructura literaria y método crítico. Madrid, Cátedra, 1975.

Sáinz de Robles, Federico C. Historia y Antología de la poesía española. Tomo I, Madrid, Aguilar, 1967.

Vivanco, Luis Felipe. Introducción a la poesía española contemporánea. $3^{\circ} \mathrm{ed}$. Tomo I, Madrid, Guadarrama, 1974. 